\title{
TNF- $\alpha$ Activates High-Mobility Group Box 1 - Toll-Like Receptor 4 Signaling Pathway in Human Aortic Endothelial Cells
}

\author{
Won Seok Yang ${ }^{\mathrm{a}}$ Nam Jeong Han ${ }^{\mathrm{b}}$ Jin Ju Kim ${ }^{\mathrm{b}}$ Mee Jeong Lee ${ }^{\mathrm{c}}$ Su-Kil Park
}

aDivision of Nephrology, Department of Internal Medicine, Asan Medical Center, University of Ulsan College of Medicine, Seoul, bAsan Institute for Life Sciences, Seoul, 'Department of Pediatrics, Dankook University College of Medicine, Cheonan, Korea

\section{Key Words}

High-mobility group box 1 - Myeloid differentiation factor 88 - Reactive oxygen species • Spleen tyrosine kinase $\cdot$ Toll-like receptor $4 \cdot$ Tumor necrosis factor- $\alpha$

\begin{abstract}
Background/Aims: Toll-like receptor 4 (TLR4) interacts with endogenous substances as well as lipopolysaccharide. We explored whether TLR4 is implicated in tumor necrosis factor- $\alpha$ (TNF- $\alpha$ ) signal transduction in human aortic endothelial cells. Methods: The pathway was evaluated by transfection of siRNAs, immunoprecipitation and Western blot analysis. Results: TNF- $\alpha$ activated spleen tyrosine kinase (Syk) within 10 min, which led to endothelin-1 (ET-1) production. TLR4 was also rapidly activated by TNF- $\alpha$ stimulation, as shown by recruitment of interleukin-1 receptor-associated kinase 1 to TLR4 and its adaptor molecule, myeloid differentiation factor 88 (MyD88). siRNA depletion of TLR4 markedly attenuated TNF- $\alpha-$ induced Syk activation and ET-1 production. TLR4 inhibitor (CLI-095), TLR4-neutralizing antibody and siRNA depletion of MyD88 also attenuated TNF- $\alpha$-induced Syk activation. Syk was co-immunoprecipitated with TLR4, and TNF- $\alpha$ activated Syk bound to TLR4. Highmobility group box 1 (HMGB1) was rapidly released and associated with TLR4 after TNF- $\alpha$ stimulation with a peak at 5 min, which was prevented by $\mathrm{N}$-acetylcysteine, an antioxidant. Glycyrrhizin (HMGB1 inhibitor), HMGB1-neutralizing antibody and siRNA depletion of HMGB1 all suppressed TNF- $\alpha$-induced Syk activation and ET-1 production. Conclusion: Upon TNF- $\alpha$ stimulation, TLR4 is activated by HMGB1 that is immediately released after the generation of reactive oxygen species, and plays a crucial role in the signal transduction.
\end{abstract}

\section{Introduction}

Tumor necrosis factor- $\alpha$ (TNF- $\alpha$ ) is implicated in the pathogenesis of a variety of disease. In atherosclerotic vascular diseases, for example, TNF- $\alpha$ is overproduced and plays a crucial role in the development of early lesions of atherosclerosis [1]. Reactive oxygen species (ROS) mediate the adverse effects of TNF- $\alpha$. In endothelial cells stimulated by TNF- $\alpha$, ROS are 
rapidly generated and induce the transcription of chemotactic factors, adhesion molecules and endothelin 1 (ET-1) [2-5]. Newly synthesized chemotactic factors and adhesion molecules recruit inflammatory cells which in turn further accelerate the vicious cycle of the inflammatory process [6]. ET-1 contributes to the formation of atherosclerotic lesion by stimulating vascular smooth muscles to proliferate and produce extracellular matrices [7].

Toll-like receptor 4 (TLR4) is a transmembrane protein that plays a key role in the innate immune response [8]. The ligand-binding site in the extracellular domain of TLR4 interacts with the pathogen associated molecular patterns (PAMPs) in the microbial species such as lipopolysaccharides (LPS), which activates TLR4 leading to cascades of intracellular signal transductions to defend against the invading pathogen [8]. Besides binding to PAMPs, TLR4 can interact with endogenous molecules released from damaged tissues (damage-associated molecular pattern molecules; DAMPs), and induces many sterile inflammatory processes [9]. High-mobility group box 1 (HMGB1) is one of the DAMPs that activate TLR4 [10].

Though TNF- $\alpha$ signal pathway has been extensively studied, it is obscure whether TLR4 is involved in TNF- $\alpha$ signal transduction. Recently, we found that TLR4 plays a critical role in high glucose signal transduction of renal tubular epithelial cells [11], in which TLR4 was activated by HMGB1. This process was provoked by ROS that were generated immediately after high glucose stimulation. Since TNF- $\alpha$ also stimulates the generation of ROS and transmits its signal through ROS as noted above, it might be possible that HMGB1-activated TLR4 constitutes a portion of TNF- $\alpha$ signaling pathway.

Spleen tyrosine kinase (Syk), a non-receptor protein tyrosine kinase, is constitutively bound to TLR4 and mediates the signal transduction of TLR4 in the hematopoietic cells [1214]. The expression of Syk is not limited to the hematopoietic cells [15-18]. In our previous study of cultured human aortic endothelial cells (HAECs) [16], Syk was rapidly activated by TNF- $\alpha$ and transmits TNF- $\alpha$ signal leading to ET- 1 gene transcription with its protein production. In this process, ROS were generated earlier than Syk activation and served as an upstream signal of Syk. However, the pathway between ROS and Syk activation has not been established. Based on the findings noted above, we hypothesized that the release of HMGB1 and subsequent activation of TLR4 could be the bridge between ROS and Syk activation after stimulation with TNF- $\alpha$.

In the present study, therefore, we tested whether TLR4 is implicated in TNF- $\alpha$ signal transduction in HAECs. And then, we explored the interaction between TLR4 and Syk. Finally, we investigated the role of HMGB1 in activation of TLR4 after TNF- $\alpha$ stimulation.

\section{Materials and Methods}

\section{Materials}

TNF- $\alpha$ was purchased from R\&D Systems (Abingdon, UK). Glycyrrhizin and N-acetylcysteine were from Sigma-Aldrich (St. Louis, MO, USA). Antibodies to human TLR4 (HTA-125, 76B357.1, H-80), HMGB1, Syk, myeloid differentiation factor 88(MyD88), interleukin-1 receptor-associated kinase 1 (IRAK-1) and actin were from Santa Cruz Biotechnology (Santa Cruz, CA, USA). Anti-TLR4 (HTA-125) antibody, a mouse monoclonal $\mathrm{IgG}_{2 \mathrm{a}^{\prime}}$ detects TLR4-myeloid differentiation factor 2 complex and was used for immunoprecipitating TLR4 in the cell lysate. Anti-TLR4 (76B357.1) antibody, a mouse monoclonal IgG $\mathrm{gb}_{2 \mathrm{~b}}$ against amino acids 100-200 of human TLR4, was used for immunofluorescent staining of cell surface TLR4. Anti-TLR4 (H-80) antibody, a rabbit polyclonal IgG, was used to detect TLR4 in Western blot analysis. Anti-phospho-Syk (pY525) antibody was from Epitomics (clone EP575(2)Y, Burlingame, CA, USA). TLR4-neutralizing antibody and control IgG were from eBioscience (San Diego, CA, USA). CLI-095 was from InvivoGen (San Diego, CA, USA). siRNAs (control-siRNA, Syk-siRNA, TLR4-siRNA, MyD88-siRNA and HMGB1-siRNA) were from Life Technologies $\left(\right.$ Ambion $^{\circledR}$ ). Anti-HMGB1 chicken IgY neutralizing polyclonal antibody and control chicken IgY were from SHINO-TEST Co. (Kanagawa, Japan).

Cell culture

HAECs were obtained from Lonza Walkersville, Inc. (Walkersville, MD, USA). The cells were cultured in EBM-2 endothelial growth basal medium (Lonza Walkersville, Inc.). The cells were used for the experiments 


\section{Cellular Physiology Cell Physiol Biochem 2016;38:2139-2151 \begin{tabular}{l|l} 
and Biochemistry Published online: May 17, 2016 & $\begin{array}{l}\text { D } 2016 \text { The Author(s). Published by S. Karger AG, Basel } \\
\text { www.karger.com/cpb }\end{array}$ \\
\hline
\end{tabular} \\ Yang et al.: HMGB1-TLR4 in TNF- $\alpha$ Signal Transduction}

after 3-5 passages. In each experiment, the cells were rested in RPMI-1640 medium containing 1\% fetal bovine serum (FBS) for $16 \mathrm{~h}$, and then the medium was replaced with serum-free RPMI-1640 followed by the addition of signal inhibitors and TNF- $\alpha$.

\section{Transfection of siRNA}

To evaluate the effects of specific depletion of Syk, TLR4, MyD88 and HMGB1 on the signal transduction of TNF- $\alpha$, Syk-siRNA, TLR4-siRNA, MyD88-siRNA and HMGB1-siRNA or a nonspecific, scrambled, controlsiRNA was transfected to the cells using Lipofectamine ${ }^{\circledR}$ Reagent (Life Technologies) as follows; $1 \times 10^{5}$ cells were seeded in each 6-well plate and cultured for $24 \mathrm{~h}$. siRNA-lipofectamine complexes were prepared by incubating siRNAs (100 pmol) with lipofectamine reagent diluted in Opti-MEM ${ }^{\circledR}$ medium (Life Technologies) for 15 minutes at room temperature. The transfection of siRNA was performed by adding the siRNAlipofectamine complexes to the cell culture dish containing serum-free culture medium and incubating the cells for $6 \mathrm{~h}$ at $37{ }^{\circ} \mathrm{C}$ in a $\mathrm{CO}_{2}$ incubator. After the transfection, the cells were cultured for $18 \mathrm{~h}$ in EBM-2 endothelial growth basal medium. Thereafter, the cells were rested for $16 \mathrm{~h}$ in RPMI-1640 containing 1\% FBS and then subjected to the experiments in serum-free RPMI-1640.

\section{Western blot analysis}

After treatment with TNF- $\alpha$ for indicated times, the culture medium was removed and the cells were washed with phosphate buffered saline (PBS). After PBS was aspirated, the cells were incubated on ice for 10 min with cold lysis buffer (50 mM Tris- $\mathrm{HCl}, \mathrm{pH} 7.4,150 \mathrm{mM} \mathrm{NaCl}, 0.25 \%$ sodium deoxycholate, $1 \% \mathrm{NP}-40$, protease and phosphatase inhibitors). After the incubation, the adherent cells were collected using a plastic cell scraper and transferred to a microcentrifuge tube. The tube containing cell lysate was centrifuged at $4{ }^{\circ} \mathrm{C}$ $(10,000 \times g)$ for $20 \mathrm{~min}$, and the supernatant was obtained as whole cell lysate. Protein concentration in each cell lysate was quantitated using Bradford method, and the cell lysates containing equal amount of proteins were separated by sodium dodecyl sulfate-polyacrylamide gel electrophoresis. The separated proteins on the gel were transferred to an Immobilon-P membrane (Millipore, Bedford, MA, USA). Subsequently, the membrane was incubated with the primary antibody, followed by washing and further incubation with horseradish peroxidase conjugated secondary antibody. Thereafter, the protein bands were visualized using an enhanced chemiluminescence agent (Luminata ${ }^{\mathrm{TM}}$ Forte Western HRP Substrate; Millipore).

To measure HMGB1 in cell culture supernatants, equal amounts of supernatants were precipitated with cold ethanol. After washing with ethanol and air dry, the samples were subjected to immunoblotting with anti-HMGB1 antibody.

\section{Immunofluorescent staining}

To assess the cell surface expression of TLR4, the cells were fixed with 4\% paraformaldehyde for 10 min without permeabilization, and incubated with 1\% bovine serum albumin in PBS for 60 min to block nonspecific binding. Thereafter, the cells were incubated with a mouse antibody against the amino acids in the extracellular domain of human TLR4 (76B357.1) overnight at $4{ }^{\circ} \mathrm{C}$, washed 3 times with PBS and then incubated with FITC-conjugated anti-mouse IgG secondary antibody. TLR4 immunoreactivity was captured using a confocal microscope.

\section{Immunoprecipitation}

Whole cell lysates were obtained and protein concentrations were quantitated as in the method for Western blot analysis. The cell lysates were incubated with anti-TLR4 (HTA-125) or anti-MyD88 antibody at $4^{\circ} \mathrm{C}$ for $2 \mathrm{~h}$, and followed by further incubation with protein $\mathrm{A} / \mathrm{G}$-agarose beads (Santa Cruz Biotechnology) at $4{ }^{\circ} \mathrm{C}$ for $16 \mathrm{~h}$ under rotary agitation. Thereafter, the samples were centrifuged at $4{ }^{\circ} \mathrm{C}(10,000 \times \mathrm{g})$ for 5 min and the supernatants were aspirated. Finally, the protein A/G-agarose beads attached with the immunecomplex were suspended in Laemmli sample buffer and subjected to Western blot analysis.

\section{Statistical analysis}

Data are presented by the number of different experiments (n) and means \pm SE (standard error). The statistical differences between the groups were determined by an analysis of variance with Dunnett multiple-comparisons test. The $p$-value less than 0.05 was considered statistically significant. 


\begin{tabular}{|c|c|c|}
\hline Cellular Physiology & Cell Physiol Biochem 2016; & 38:2139-2151 \\
\hline and Biochemistrv & $\begin{array}{l}\text { DOI: 10.1159/000445570 } \\
\text { Published online: May 17, } 2016\end{array}$ & $\begin{array}{l}\text { O } 2016 \text { The Author(s). Published by S. Karger AG, Basel } \\
\text { www.karger.com/cpb }\end{array}$ \\
\hline
\end{tabular}

\section{Results}

TNF- $\alpha$ stimulates ET-1 production through activation of Syk

First, we examined the effect of TNF- $\alpha$ on Syk activation in HAECs. The activation of Syk was assessed by measuring Tyr525 phosphorylation of Syk [19]. At the concentrations between 1 and $10 \mathrm{ng} / \mathrm{ml}$, TNF- $\alpha$ stimulated Syk activation in dose- and time-dependent manners (Fig. 1A \& 1B). To further examine whether Syk mediates TNF- $\alpha$-induced ET-1 production, HAECs were depleted of Syk by siRNA transfection and treated with TNF- $\alpha$. As shown in Fig. 1C, depletion of Syk suppressed TNF- $\alpha$-induced ET-1 protein expression.

TNF- $\alpha$-induced Syk activation and ET-1 production are inhibited by depletion of TLR4

We next examined whether TLR4 is implicated in TNF- $\alpha$ signal transduction. Transfection of the cells with TLR4-siRNA resulted in a decrease in the cell surface expression of TLR4 (Fig 2A). To test the effect of depletion of cell surface TLR4 on TNF- $\alpha$-induced Syk activation, we transfected HAECs with control-siRNA or TLR4-siRNA, and treated the cells with or without TNF- $\alpha$ for 10 min. Thereafter, Syk activation was assessed in the whole cell lysates. As shown in Fig. 2B, the stimulatory effect of TNF- $\alpha$ on Syk activation was attenuated when TLR4 was depleted.

Similarly, we transfected HAECs with control-siRNA or TLR4-siRNA, and treated the cells with or without TNF- $\alpha$ for $24 \mathrm{~h}$. Thereafter, ET-1 in the whole cell lysate was measured by Western blot analysis. TNF- $\alpha$ significantly increased ET-1 protein as compared with control, while the stimulatory effect of TNF- $\alpha$ was attenuated when TLR4 was depleted. (Fig. 2C)

TLR4 inhibitors suppress TNF- $\alpha$-induced Syk activation

In addition to depletion of TLR4, we tested whether direct inhibition of TLR4 by either a chemical inhibitor CLI-095 (also known as TAK-242) or TLR4-neutralizing antibody

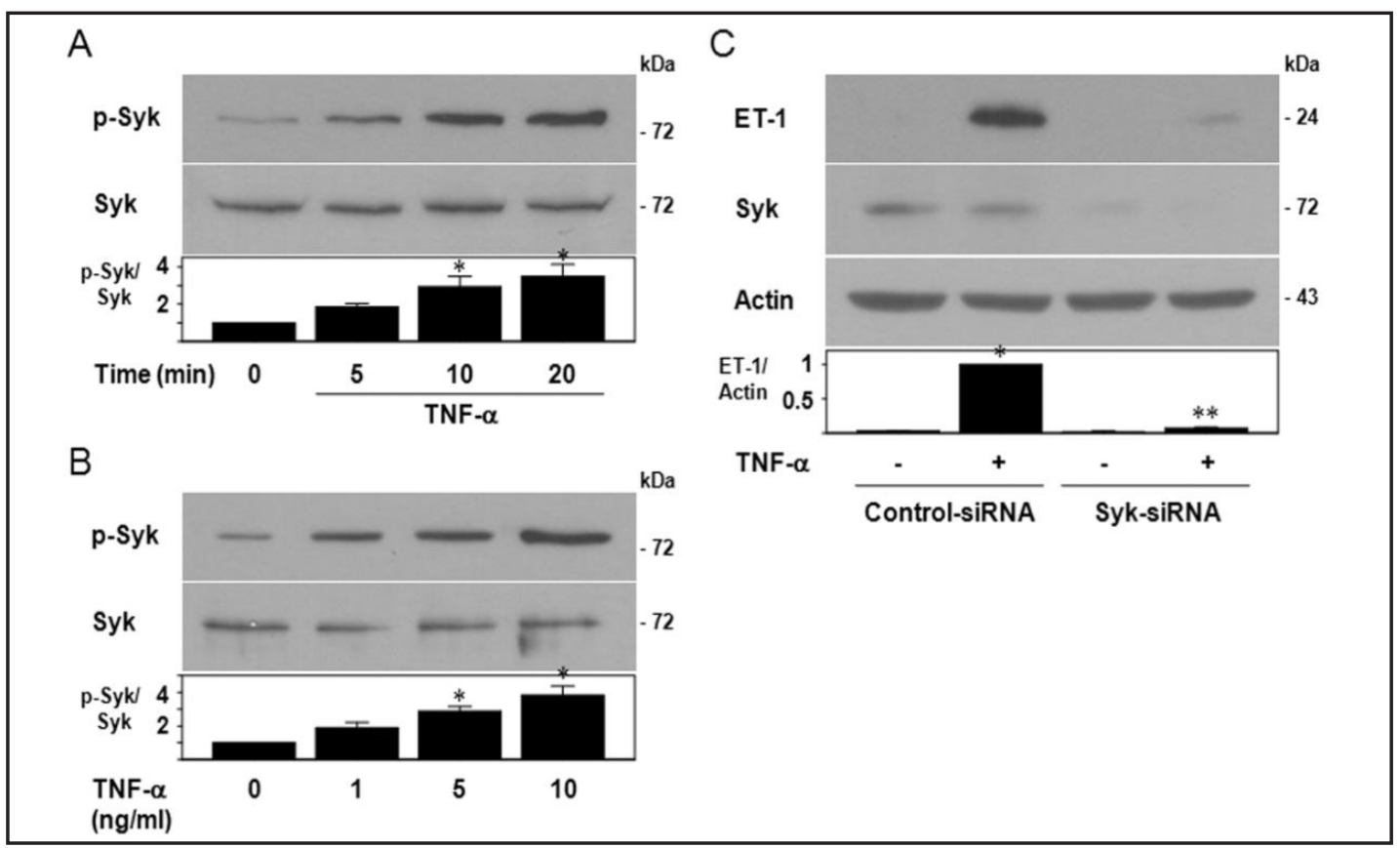

Fig. 1. TNF- $\alpha$ stimulates ET-1 production through activation of Syk in HAECs. (A) HAECs were treated with TNF- $\alpha(10 \mathrm{ng} / \mathrm{ml})$ for $0,5,10$ and $20 \mathrm{~min}(\mathrm{n}=4)$. (B) HAECs were treated with different doses of TNF- $\alpha$ for 10 min (n=4). p-Syk (Tyr525) and total Syk in whole cell lysates were measured by Western blot analysis ( ${ }^{*} \mathrm{p}<0.05$ compared with control) (C) HAECs were transfected with control-siRNA or Syk-siRNA, and then treated with or without TNF- $\alpha(10 \mathrm{ng} / \mathrm{ml})$ for $24 \mathrm{~h}(\mathrm{n}=3)$. ET-1 in whole cell lysates was measured by Western blot analysis. ( ${ }^{*} \mathrm{p}<0.05$ compared with control-siRNA only, ${ }^{* *} \mathrm{p}<0.05$ as compared with control-siRNA plus TNF- $\alpha$ ).

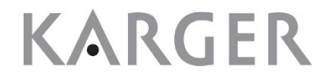




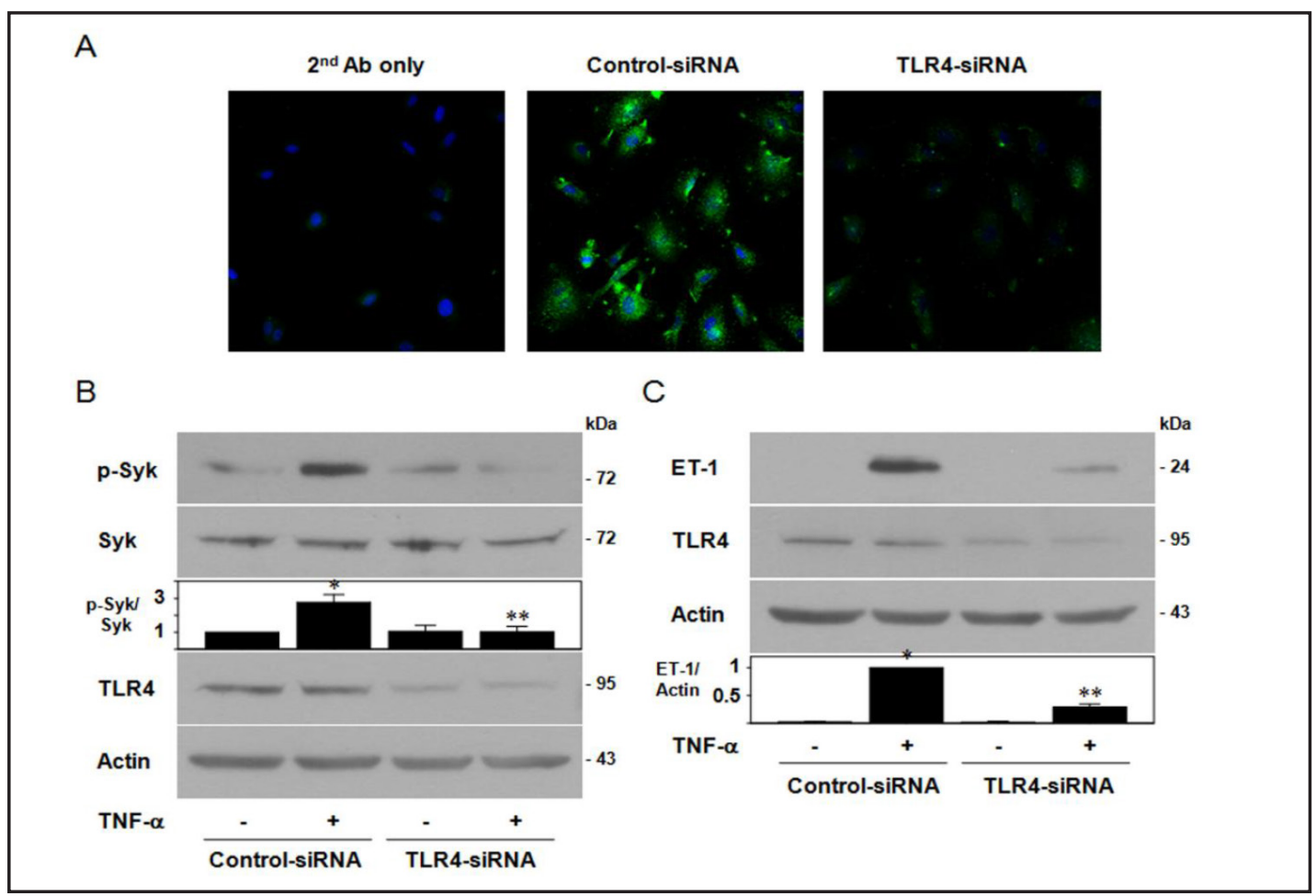

Fig. 2. TNF- $\alpha$-induced Syk activation and ET-1 production are inhibited by depletion of TLR4. (A) Immunofluorescence microscopy of TLR4 expression. HAECs were transfected with control-siRNA or TLR4-siRNA. Forty-eight hours after the beginning of transfection, the cells were immunostained for TLR4 without permeabilization, and visualized with confocal microscopy. Cell nuclei were stained with DAPI. Representative images from three independent experiments with similar results are shown. (B,C) Effect of TLR4 depletion on TNF- $\alpha$-induced Syk activation and ET-1 production. HAECs were transfected with control-siRNA or TLR4-siRNA, and then incubated with or without TNF- $\alpha(10 \mathrm{ng} / \mathrm{ml})$ for $10 \mathrm{~min}(\mathrm{~B})(\mathrm{n}=4)$ or $24 \mathrm{~h}(\mathrm{C})(\mathrm{n}=3)$. p-Syk (Tyr525), total Syk, ET-1, TLR4 and actin in whole cell lysates were measured by Western blot analysis. ( ${ }^{*} \mathrm{p}<0.05$ compared with control-siRNA only, ${ }^{* *} \mathrm{p}<0.05$ as compared with control-siRNA plus TNF- $\alpha$ ).

interferes with TNF- $\alpha$ signal transduction. CLI-095 inhibits TLR4 by selectively binding to TLR4 and interfering with its interaction with adaptor molecules [20]. As shown in Fig. 3A, CLI-095 inhibited TNF- $\alpha$-induced Syk activation in a dose dependent manner. Likewise, TLR4-neutralizing antibody $(5 \mu \mathrm{g} / \mathrm{ml})$ attenuated the stimulatory effect of TNF- $\alpha$ on Syk activation (Fig. 3B).

\section{Involvement of MyD88 in TNF- $\alpha$-induced Syk activation}

MyD88 is an adaptor molecule of TLR4. On activation of TLR4, MyD88 recruits IRAK1 , which transmits the signal to downstream molecules on the signal pathway $[13,21]$. Thus, increased binding of IRAK-1 to both MyD88 and TLR4 could be an evidence of TLR4 activation. To examine whether TNF- $\alpha$ activates TLR4, we treated HAECs with TNF- $\alpha$ for 0 , 5, 10 or 20 min. Thereafter, MyD88 and TLR4 in whole cell lysates were immunoprecipitated using anti-MyD88 and anti-TLR4 antibodies, respectively. The amount of IRAK-1 bound to MyD88 or TLR4 was measured by Western blot analysis of the immunoprecipitates using anti-IRAK-1 antibody. As shown in Fig. 4A and 4B, TNF- $\alpha$ rapidly increased the amount of IRAK-1 in both MyD88 and TLR4 immunoprecipitates, with a peak at $10 \mathrm{~min}$.

In another experiment, we examined whether MyD88 is required for TNF- $\alpha$-induced Syk activation. Transfection of MyD88-siRNA resulted in a significant depletion of MyD88 in the cells. siRNA depletion of MyD88 markedly inhibited TNF- $\alpha$-induced Syk activation (Fig 4C).

\section{KARGER}



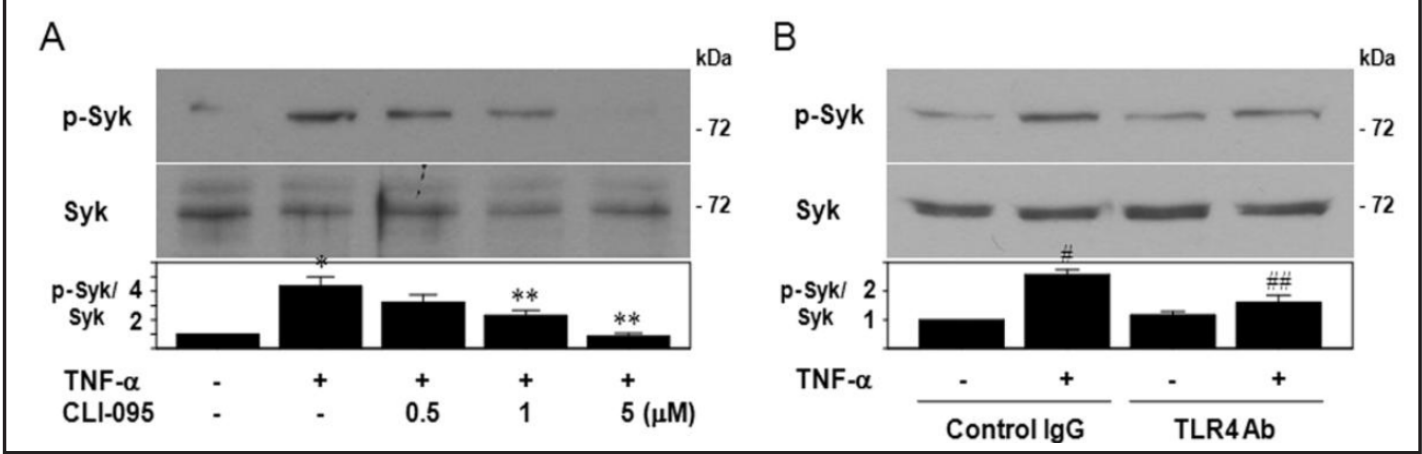

Fig. 3. TLR4 inhibitors suppress TNF- $\alpha$-induced Syk activation. HAECs preincubated with or without CLI095 (A) or TLR4-neutralizing antibody ( $5 \mu \mathrm{g} / \mathrm{ml}$ ) (B) for $30 \mathrm{~min}$ were treated with TNF- $\alpha$ (10 $\mathrm{ng} / \mathrm{ml})$ for 10 min. p-Syk (Tyr525) and total Syk in whole cell lysates were measured by Western blot analysis $\left(n=4,{ }^{*} \mathrm{p}<\right.$ 0.05 compared with control, ${ }^{* *} \mathrm{p}<0.05$ as compared with TNF- $\alpha ; \mathrm{n}=3,{ }^{\#} \mathrm{p}<0.05$ compared with control IgG only, ${ }^{\# \#} \mathrm{p}<0.05$ as compared with control IgG plus TNF- $\alpha$ ).

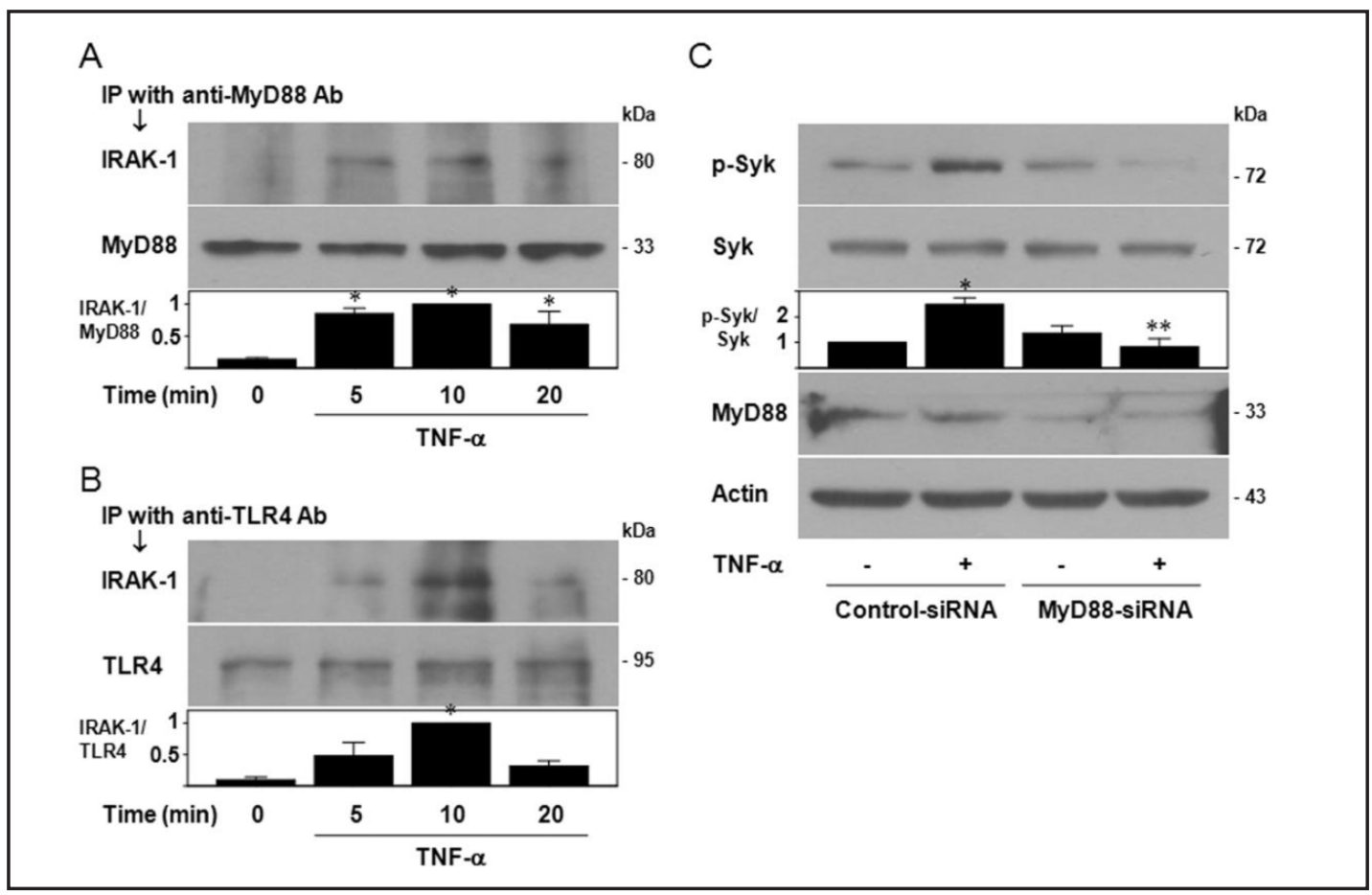

Fig. 4. Involvement of MyD88 in TNF- $\alpha$-induced Syk activation. (A, B) TNF- $\alpha$ stimulates the binding of IRAK-1 to MyD88 and TLR4. HAECs were treated with TNF- $\alpha$ (10 ng/ml) for 0, 5, 10 or $20 \mathrm{~min}$. Whole cell lysates were immunoprecipitated with an antibody to MyD88 (n=4) (A) or TLR4 (n=3) (B), and then IRAK-1 in the immunoprecipitates was measured by Western blot analysis. ( ${ }^{*} p<0.05$ compared with control) (C) Depletion of MyD88 attenuates TNF- $\alpha$-induced Syk activation. HAECs transfected with control-siRNA or MyD88-siRNA were treated with or without TNF- $\alpha(10 \mathrm{ng} / \mathrm{ml})$ for $10 \mathrm{~min}$. p-Syk (Tyr525), total Syk, MyD88 and actin in whole cell lysates were measured by Western blot analysis. ( $\mathrm{n}=3,{ }^{*} \mathrm{p}<0.05$ compared with control-siRNA only, ${ }^{* *}$ p $<0.05$ as compared with control-siRNA plus TNF- $\alpha$ ).

TNF- $\alpha$ stimulates activation of Syk that is associated with TLR4

Syk is constitutively associated with TLR4 and transmits the signal of TLR4 in hematopoietic cells [12-14]. To determine whether this is also the case in HAECs, we examined the interaction between TLR4 and Syk. HAECs were treated with TNF- $\alpha$ for 0 , 
Fig. 5. TNF- $\alpha$ stimulates activation of Syk that is associated with TLR4. HAECs were treated with TNF- $\alpha$ (10 ng/ $\mathrm{ml}$ ) for $0,5,10$ or $20 \mathrm{~min}$. Whole cell lysates were immunoprecipitated with an anti-TLR4 antibody, and then p-Syk (Tyr525), total Syk and TLR4 in the immunoprecipitates were measured by Western blot analysis. ( $\mathrm{n}=4,{ }^{*} \mathrm{p}<0.05$ compared with control).

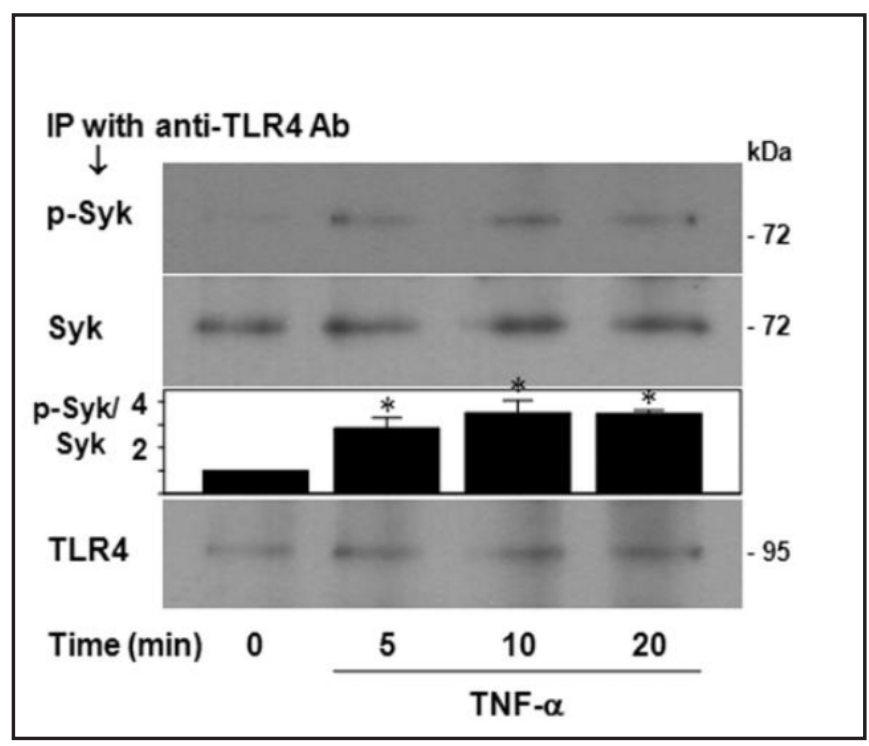

5, 10 or $20 \mathrm{~min}$. Thereafter, TLR4 in whole cell lysate was immunoprecipitated using antiTLR4 antibody. The amount of Syk and p-Syk bound to TLR4 were measured by Western blot analysis of the immunoprecipitates using anti-Syk and anti-phospho-Syk (Tyr525) antibodies, respectively. As shown in Fig. 5, Syk was detected in the immunopreciptates and the amount of Syk associated with TLR4 was not changed by TNF- $\alpha$. However, TNF- $\alpha$ stimulated the activation of Syk that was associated with TLR4.

HMGB1 is released immediately upon TNF- $\alpha$ stimulation and binds to TLR4; dependent on ROS

We examined whether HMGB1 is the ligand activating TLR4 in the cells treated with TNF- $\alpha$. HAECs were treated with TNF- $\alpha$ for $0,2.5,5,7.5$ or 10 min. Thereafter, TLR4 in whole cell lysate was immunoprecipitated using anti-TLR4 antibody. The amount of HMGB1 bound to TLR4 was measured by Western blot analysis of the immunoprecipitates using anti-HMGB1 antibody. As shown in Fig. 6A, HMGB1 was detected in the immunopreciptates and the amount of HMGB1 bound to TLR4 was rapidly increased by TNF- $\alpha$, with a peak at 5 min. To test the specificity of HMGB1 band, we incubated the cells with TNF- $\alpha$ for 5 min in the presence or absence of HMGB1-neutralizing antibody or control IgY. As shown in Fig. 6B, the presence of HMGB1-neutralizing antibody in the culture medium significantly reduced the amount of HMGB1 immunoprecipitated with anti-TLR4 antibody in the cells stimulated with TNF- $\alpha$, while control IgY did not.

Next, we examined whether ROS are implicated in the interaction of HMGB1 with TLR4 by measuring the effect of $\mathrm{N}$-acetylcysteine, a scavenger of ROS, on it. As shown in Fig. 6C, $\mathrm{N}$-acetylcysteine attenuated the stimulatory effect of TNF- $\alpha$ on the binding of HMGB1 to TLR4.

In the following experiment, we checked whether HMGB1 is released to the outside of the cells upon stimulation with TNF- $\alpha$ and whether ROS are implicated in the release of HMGB1. HAECs were preincubated with or without N-acetylcysteine for $30 \mathrm{~min}$, and further incubated with TNF- $\alpha$ for $5 \mathrm{~min}$, and the cell culture supernatants were obtained. Binding of extracellularly released HMGB1 to the receptors on the cell surface, such as TLR4, may prevent the detection of HMGB1 in the culture medium. To capture released HMGB1 and hold it in the culture medium, we added HMGB1-neutralizing antibody to the culture medium of each group of the cells (control, TNF- $\alpha$, TNF- $\alpha+\mathrm{N}$-acetylcysteine) before treatment with TNF- $\alpha$. The proteins in the conditioned medium were concentrated by cold ethanol precipitation and subjected to Western blot analysis using anti-HMGB1 antibody. As shown in Fig. 6D, TNF- $\alpha$ treatment increased HMGB1 in the culture medium of the cells, while this effect of TNF- $\alpha$ was largely prevented by $\mathrm{N}$-acetylcysteine. 

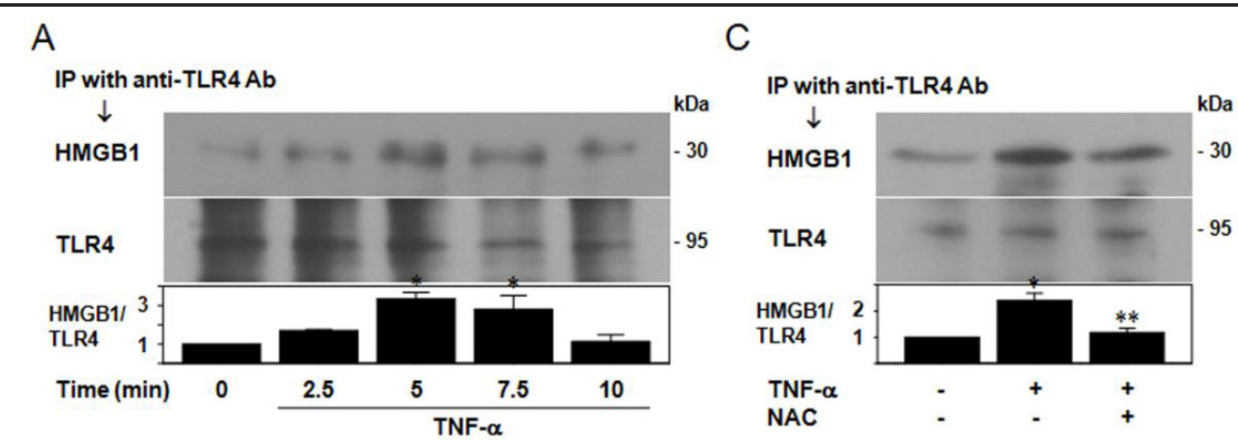

\section{B}

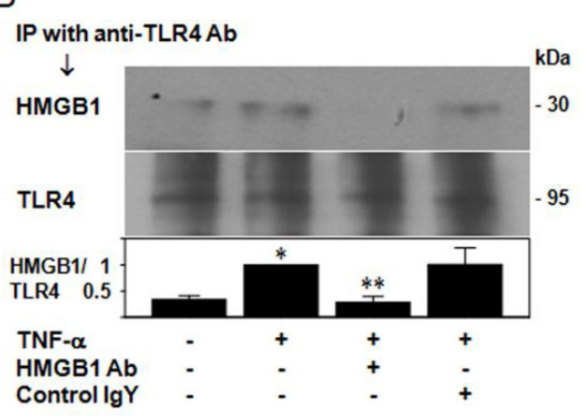

D

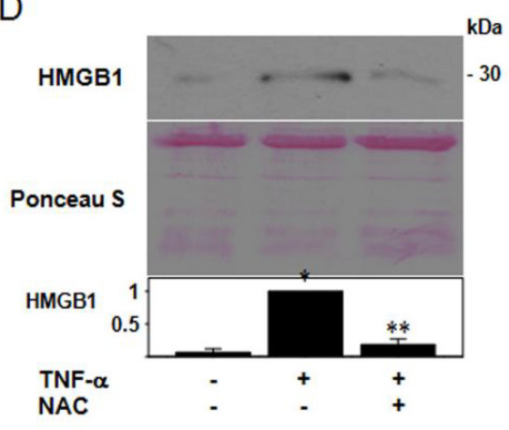

Fig. 6. HMGB1 is released immediately upon TNF- $\alpha$ stimulation and binds to TLR4, while this effect of TNF- $\alpha$ is attenuated by N-acetylcysteine, a ROS scavenger. (A) TNF- $\alpha$ increases the binding of HMGB1 to TLR4. HAECs were treated with TNF- $\alpha(10 \mathrm{ng} / \mathrm{ml})$ for $0,2.5,5,7.5$ or $10 \mathrm{~min}$. Whole-cell lysates were immunoprecipitated with an anti-TLR4 antibody, and then HMGB1 in the immunoprecipitates was measured by Western blot analysis. ( $\mathrm{n}=4,{ }^{*} \mathrm{p}<0.05$ compared with control). (B) Binding of HMGB1 to TLR4 is prevented by HMGB1-neutralizing antibody. HAECs were treated with TNF- $\alpha(10 \mathrm{ng} / \mathrm{ml})$ for $5 \mathrm{~min}$ in the presence or absence of HMGB1-neutralizing antibody or control IgY. Whole cell lysates were immunoprecipitated with an anti-TLR4 antibody, and then HMGB1 in the immunoprecipitates was measured by Western blot analysis. ( $\mathrm{n}=4,{ }^{*} \mathrm{p}<0.05$ compared with control, ${ }^{*} \mathrm{p}<0.05$ as compared with TNF- $\alpha$ ). (C) N-acetylcysteine reduces TNF- $\alpha$-induced binding of HMGB1 to TLR4. HAECs preincubated with or without $\mathrm{N}$-acetylcysteine $(5 \mathrm{mM})$ for $30 \mathrm{~min}$ were treated with TNF- $\alpha(10 \mathrm{ng} / \mathrm{ml})$ for $5 \mathrm{~min}$. Whole cell lysates were immunoprecipitated with an anti-TLR4 antibody, and then HMGB1 in the immunoprecipitates was measured by Western blot analysis. ( $\mathrm{n}=3,{ }^{*} \mathrm{p}<0.05$ compared with control, ${ }^{* *} \mathrm{p}<0.05$ as compared with TNF- $\alpha$ ). (D) TNF- $\alpha$ increases extracellular release of HMGB1, while N-acetylcysteine attenuates this effect of TNF- $\alpha$. HAECs were preincubated with or without N-acetylcysteine for $30 \mathrm{~min}$, and further incubated with TNF- $\alpha$ for 5 min. Before TNF- $\alpha$ treatment, HMGB1-neutralizing antibody $(10 \mu \mathrm{g} / \mathrm{ml})$ was added to each group of the cells (control, TNF- $\alpha$, TNF- $\alpha+N$-acetylcysteine) to capture released HMGB1 and hold it in the culture medium. The proteins in the conditioned medium were concentrated by cold ethanol precipitation and subjected to Western blot analysis using anti-HMGB1 antibody. Ponceau S stain was used to compare the amount of protein loading. ( $\mathrm{n}=3,{ }^{*} \mathrm{p}<0.05$ compared with control, $" \mathrm{p}<0.05$ as compared with TNF- $\alpha$ ).

TNF- $\alpha$-induced Syk activation and ET-1 production are attenuated by inhibitors or siRNA depletion of HMGB1

We further examined whether HMGB1 is implicated in TNF- $\alpha$-induced Syk activation and ET-1 production by measuring the effects of glycyrrhizin, HMGB1-neutralizing antibody and siRNA depletion of HMGB1. Glycyrrhizin, derived from licorice roots, is known to bind directly to HMGB1 and inhibit its activity [22]. As shown in Fig. 7A \& 7B, glycyrrhizin inhibited TNF- $\alpha$-induced Syk activation and ET-1 production. Likewise, specific inhibition by HMGB1-neutralizing antibody and siRNA depletion of HMGB1 both inhibited TNF- $\alpha$-induced Syk activation and ET-1 production (Fig. 7C-7F). 

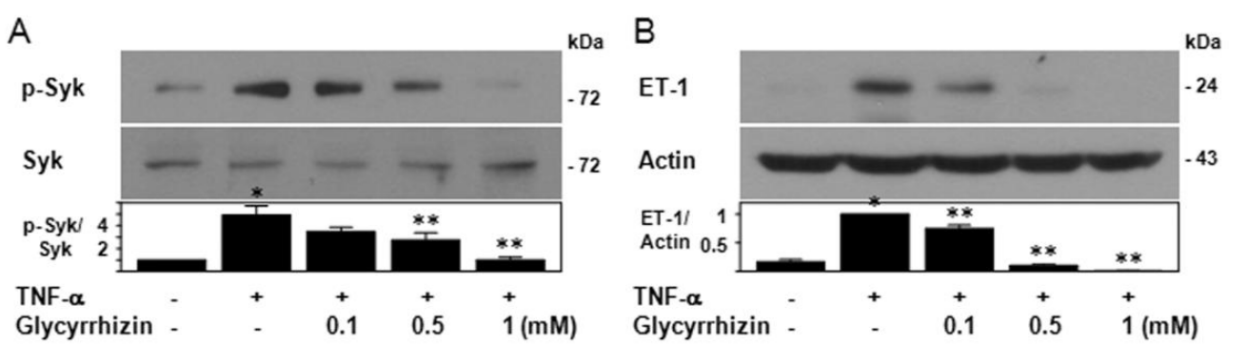

C

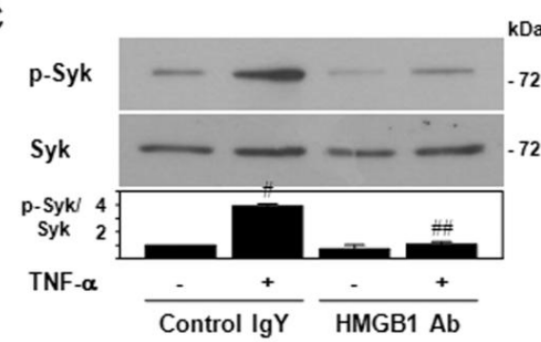

D

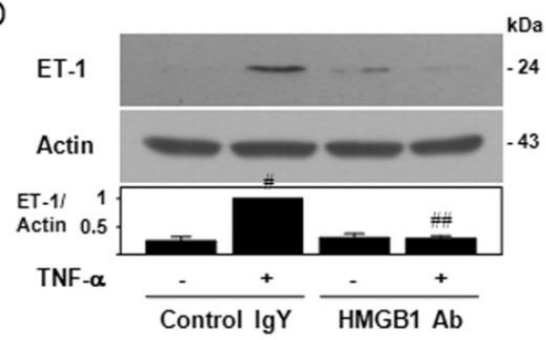

$\mathrm{E}$

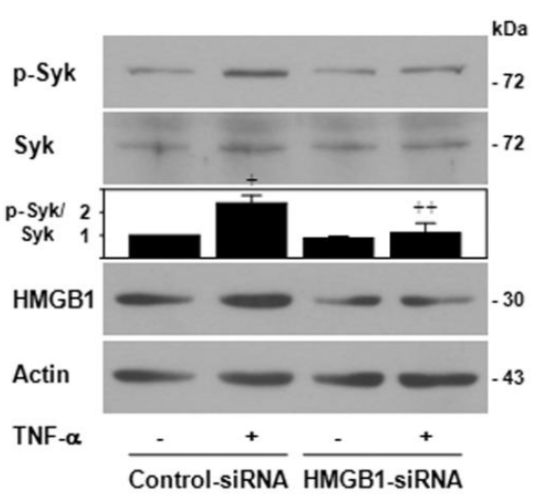

F

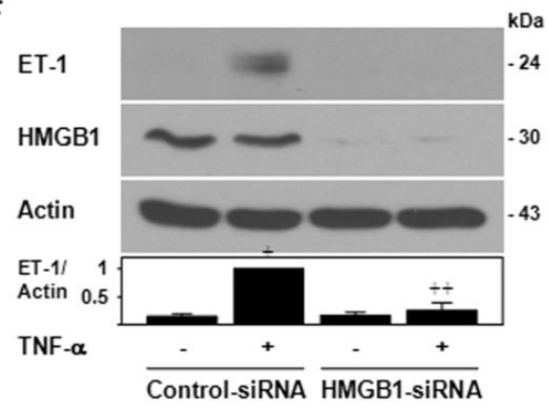

Fig. 7. TNF- $\alpha$-induced Syk activation and ET-1 production are attenuated by inhibitors or siRNA depletion of HMGB1. (A, B) HAECs were treated for $10 \min (A)(n=4)$ or $24 \mathrm{~h}(\mathrm{~B})(\mathrm{n}=3)$ with TNF- $\alpha(10 \mathrm{ng} / \mathrm{ml})$ together with different doses of glycyrrhizin, an inhibitor of HMGB1. (C, D) HAECs preincubated with or without control IgY or HMGB1-neutralizing antibody $(10 \mu \mathrm{g} / \mathrm{ml})$ for 1 min were treated with TNF- $\alpha(10 \mathrm{ng} / \mathrm{ml})$ for $10 \min (C)(n=3)$ or $24 \mathrm{~h}(\mathrm{D})(\mathrm{n}=3)$. (E, F) HAECs were transfected with control-siRNA or TLR4-siRNA, and then incubated with or without TNF- $\alpha(10 \mathrm{ng} / \mathrm{ml})$ for $10 \mathrm{~min}(\mathrm{E})(\mathrm{n}=3)$ or $24 \mathrm{~h}(\mathrm{~F})(\mathrm{n}=3)$. p-Syk (Tyr525), total Syk, ET-1, HMGB1 and actin in whole cell lysates were measured by Western blot analysis. ( $\mathrm{p} p<0.05$ compared with control, " $\mathrm{p}<0.05$ as compared with TNF- $\alpha$; ${ }^{\#} \mathrm{p}<0.05$ compared with control IgY only, ${ }^{\# \#} \mathrm{p}$ $<0.05$ as compared with control IgY plus TNF- $\alpha$; ${ }^{+} \mathrm{p}<0.05$ compared with control-siRNA only, ${ }^{++} \mathrm{p}<0.05$ as compared with control-siRNA plus TNF- $\alpha$ ).

$N$-acetylcysteine inhibits TNF- $\alpha$-induced Syk activation and ET-1 production

Because N-acetylcysteine markedly reduced the extracellular release of HMGB1 and its binding to TLR4 in the cells treated with TNF- $\alpha$, we examined the effects of $\mathrm{N}$-acetylcysteine on the activation of Syk, the downstream step of TLR4, and the production of ET-1. As shown in Fig 8, N-acetylcysteine attenuated TNF- $\alpha$-induced Syk activation and ET-1 expression.

\section{Discussion}

In the present study, we explored the possible role of TLR4 in TNF- $\alpha$ signal transduction. Our data show that HMGB1-TLR4 axis is implicated in TNF- $\alpha$ signal transduction as follows; upon stimulation with TNF- $\alpha$, ROS are immediately generated and induce extracellular 


\section{Cellular Physiology Cell Physiol Biochem 2016;38:2139-2151 \begin{tabular}{c|c|c|c|} 
DOI: 10.1159/000445570 & $\begin{array}{l}\text { O 2016 The Author(s). Published by S. Karger AG, Basel } \\
\text { www.karger.com/cpb }\end{array}$
\end{tabular} \\ Yang et al.: HMGB1-TLR4 in TNF- $\alpha$ Signal Transduction}

Fig. 8. N-acetylcysteine inhibits TNF- $\alpha$-induced Syk activation and ET-1 production. HAECs preincubated with or without $\mathrm{N}$-acetylcysteine $(5 \mathrm{mM})$ for $30 \mathrm{~min}$ were incubated with TNF- $\alpha$ (10 ng/ $\mathrm{ml}$ ) for $10 \mathrm{~min}$ (A) or $24 \mathrm{~h}$ (B). p-Syk (Tyr525), total Syk, ET-1 and actin in whole cell lysates were measured by Western blot analysis. $\left(n=3,{ }^{*} p<\right.$ 0.05 compared with control, ${ }^{* *} \mathrm{p}<0.05$ as compared with TNF- $\alpha$ ).

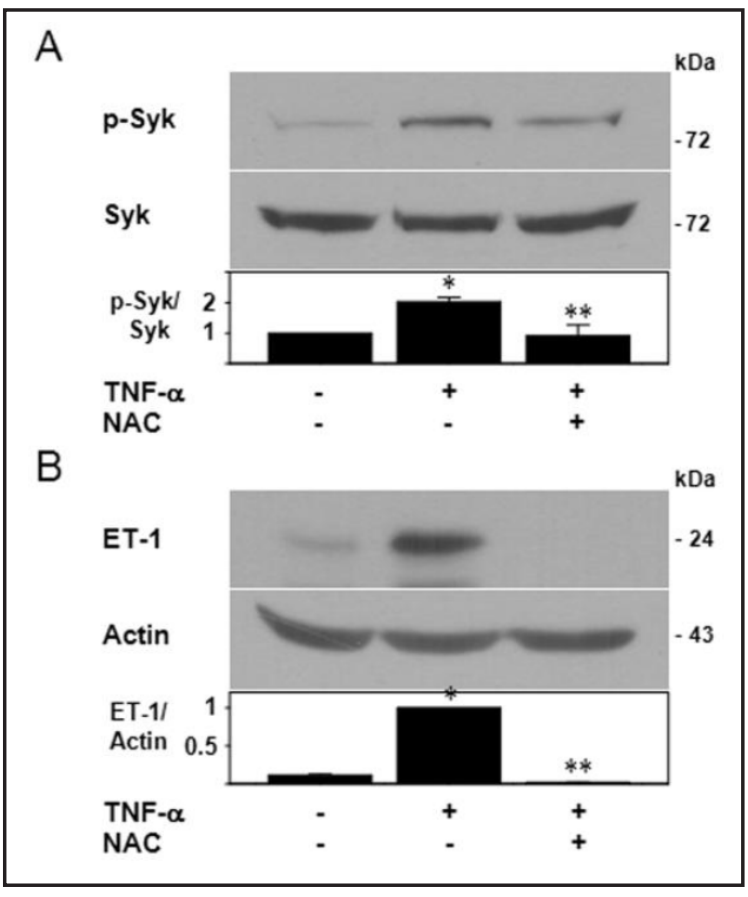

release of HMGB1 which in turn binds to TLR4 and activates it, leading to activations of Syk and MyD88, the adaptor molecules.

So far, TNF- $\alpha$ signal pathway has been extensively studied, but it is not known whether TLR4 participates in TNF- $\alpha$ signal transduction. When TLR4 is activated by interaction with LPS, MyD88, an adaptor molecule of TLR4, recruits IRAK-1 to activate the downstream signal molecules $[13,21]$. Likewise, TNF- $\alpha$, in the present study, rapidly increased the binding of IRAK-1 to MyD88 and thereby to TLR4. These findings coincide with the previous studies demonstrating that IRAK- 1 is activated by TNF- $\alpha$ stimulation and mediates nuclear factor$\kappa \mathrm{B}$ activation $[23,24]$. The activation of TLR4 was crucial for subsequent Syk activation since siRNA depletion of TLR4 suppressed TNF- $\alpha$-induced Syk activation and ET-1 protein expression. In addition, TLR4 inhibition either by CLI-095 or TLR4-neutralizing antibody suppressed TNF- $\alpha$-induced Syk activation. These findings demonstrate that TLR 4 is activated after TNF- $\alpha$ stimulation and plays a crucial role in the signal transduction.

TLR4 activation is initiated by binding of a ligand to the receptor. In the present study, HMGB1 was the ligand activating TLR4 after TNF- $\alpha$ stimulation. Besides binding to PAMPs such as LPS, TLR4 reacts with endogenous substances, i.e., DAMPs [9]. HMGB1 is one of DAMPs that can activate TLR4 [10]. Normally, it is present in the nucleus and has an important function by binding to DNA and bending it to allow the binding of transcriptional factors [25]. In response to proinflammatory cytokines as well as infection, HMGB1 can be released extracellularly and plays as a danger signal that activates the innate immune response [25]. TNF- $\alpha$ is one of the stimuli to the secretion of HMBG1. HMGB1 in culture medium, as measured by ELISA or Western blot analysis, was shown to increase after TNF- $\alpha$ stimulation [26-28]. However, the increase of HMGB1 in cell culture medium was significant at least several hours after the stimulation, and the role of HMGB1 in TNF- $\alpha$ signal transduction has not been addressed. By contrast, the present study shows that there is an immediate extracellular release of HMGB1 after TNF- $\alpha$ stimulation. HMGB1 was coimmunoprecipitated with TLR4, and the amount of HMGB1 bound to TLR4 increased shortly after exposure to TNF- $\alpha$. On the other hand, glycyrrhizin, HMGB1-neutralizing antibody and depletion of HMGB1 by siRNA transfection all inhibited TNF- $\alpha$-induced Syk activation and ET-1 production. The findings together demonstrate that HMGB1 is immediately released after TNF- $\alpha$ stimulation, and binds and activates TLR4 on the cell surface. 


\section{Cellular Physiology Cell Physiol Biochem 2016;38:2139-2151 \begin{tabular}{l|l|l} 
and Biochemistry 10.1159/000445570 & $\begin{array}{l}\text { D) 2016 The Author(s). Published by S. Karger AG, Basel } \\
\text { www.karger.com/cpb }\end{array}$ \\
\hline Published online: May 17, 2016 &
\end{tabular} \\ Yang et al.: HMGB1-TLR4 in TNF- $\alpha$ Signal Transduction}

It is well established that ROS are produced after TNF- $\alpha$ stimulation in a variety of cell types including HAECs [5, 29]. In the present study, N-acetylcysteine, a ROS scavenger, markedly prevented TNF- $\alpha$-induced extracellular release of HMGB1 and thereby the binding of it to TLR4. It also inhibited TNF- $\alpha$-induced Syk activation and ET- 1 expression, the downstream steps of TLR4. Therefore, ROS were considered to be implicated in the immediate extracellular release of HMGB1 after TNF- $\alpha$ stimulation. It is consistent with our previous study of renal tubular epithelial cells [11] in which high glucose stimulation caused an immediate increase in the association of HMGB1 with TLR4, and this effect of high glucose was dependent on ROS production. ROS are generated by a variety of stimuli and act as a signaling molecule [30,31], and our data suggest that HMGB1-TLR4 axis could be a common downstream signal of ROS.

Upon binding of the ligand to TLR4, the adaptor proteins TIRAP, MyD88 and TRAM are recruited to the cytoplasmic domain of the receptor, which activates TIRAP-MyD88-IRAK and TRAM-TRIF-IRF3 pathways [21]. Besides the well-known adaptor proteins, Syk was found to be constitutively associated with TLR4 in hematopoietic cells including neutrophils, monocytes and macrophages [12-14], by interaction between the N-terminal SH2 domain of Syk and the cytoplasmic TIR domain of TLR4 [32]. LPS stimulation activates Syk that is constitutively bound to TLR4 $[12,13]$. In the present study, Syk in HAECs was constitutively associated with TLR4, as in the hematopoietic cells. TNF- $\alpha$ did not increase the binding of Syk to TLR4, but stimulated the activation of Syk associated with TLR4, while siRNA depletion of Syk suppressed TNF- $\alpha$-induce ET-1 production. Since Syk activation was dependent on TLR4 as noted above, Syk bound to TLR4 seems to play a key role in the signal transduction of TLR4 that is activated by TNF- $\alpha$. For the activation of Syk, MyD88 was also required since depletion of MyD88 inhibited TNF- $\alpha$-induced Syk activation.

In summary, upon stimulation of HAECs with TNF- $\alpha$, HMGB1 is immediately released to the outside of the cells, and HMGB1-TLR4 axis is activated. The release of HMGB1 is dependent on ROS generated after TNF- $\alpha$ stimulation. Activated TLR4 in turn transfers the signal to Syk as well as other adaptor molecules. In this way, HMGB1-TLR4 axis plays a crucial role in TNF- $\alpha$ signal transduction.

\section{Acknowledgement}

This study was supported by a grant (02-200) from the Asan Institute for Life Sciences (Seoul, Korea).

\section{Disclosure Statement}

The authors declare no potential conflict of interest.

\section{References}

1 Kleinbongard P, Heusch G, Schulz R: TNF $\alpha$ in atherosclerosis, myocardial ischemia/reperfusion and heart failure. Pharmacol Ther 2010;127:295-314.

2 Chen XL, Zhang Q Zhao R, Medford RM: Superoxide, $\mathrm{H}_{2} \mathrm{O}_{2}$, and iron are required for TNF- $\alpha$-induced MCP1 gene expression in endothelial cells: role of Rac1 and NADPH oxidase. Am J Physiol Heart Circ Physiol 2004;286:H1001-H1007.

3 Wang ZM, Gao W, Wang H, Zhao D, Nie ZL, Shi JQ Zhao S, Lu X, Wang LS, Yang ZJ: Green tea polyphenol epigallocatechin-3-gallate inhibits TNF- $\alpha$-induced production of monocyte chemoattractant protein-1 in human umbilical vein endothelial cells. Cell Physiol Biochem 2014;33:1349-1358. 


\section{Cellular Physiology Cell Physiol Biochem 2016;38:2139-2151 \begin{tabular}{l|l|l|}
\hline DOI: 10.1159/000445570 & $\begin{array}{l}\text { C) 2016 The Author(s). Published by S. Karger AG, Basel } \\
\text { www.karger.com/cpb }\end{array}$
\end{tabular} \\ Yang et al.: HMGB1-TLR4 in TNF- $\alpha$ Signal Transduction}

4 Arai T, Kelly SA, Brengman ML, Takano M, Smith EH, Goldschmidt-Clermont PJ, Bulkley GB: Ambient but not incremental oxidant generation effects intercellular adhesion molecule 1 induction by tumour necrosis factor $\alpha$ in endothelium. Biochem J 1998;331:853-861.

5 Yang WS, Chang JW, Han NJ, Park SK: Darbepoetin alfa suppresses tumor necrosis factor- $\alpha$-induced endothelin-1 production through antioxidant action in human aortic endothelial cells: role of sialic acid residues. Free Radic Biol Med 2011;50:1242-1251.

6 Tuttolomondo A, Di Raimondo D, Pecoraro R, Arnao V, Pinto A, Licata G: Atherosclerosis as an inflammatory disease. Curr Pharm Des 2012;18:4266-4288.

7 Ivey ME, Osman N, Little PJ: Endothelin-1 signalling in vascular smooth muscle: pathways controlling cellular functions associated with atherosclerosis. Atherosclerosis 2008;199:237-247.

8 Kumar H, Kawai T, Akira S: Toll-like receptors and innate immunity. Biochem Biophys Res Commun 2009;388:621-625.

9 Yu L, Wang L, Chen S: Endogenous toll-like receptor ligands and their biological significance. J Cell Mol Med 2010;14:2592-2603.

10 Yanai H, Ban T, Taniguchi T: High-mobility group box family of proteins: ligand and sensor for innate immunity. Trends Immunol 2012;33:633-640.

11 Yang WS, Kim JS, Han NJ, Lee MJ, Park SK: Toll-like receptor 4/spleen tyrosine kinase complex in high glucose signal transduction of proximal tubular epithelial cells. Cell Physiol Biochem 2015;35:2309-2319.

12 Arndt PG, Suzuki N, Avdi NJ, Malcolm KC, Worthen GS: Lipopolysaccharide-induced c-Jun $\mathrm{NH}_{2}$-terminal kinase activation in human neutrophils: role of phosphatidylinositol 3-kinase and Syk-mediated pathways. J Biol Chem 2004;279:10883-10891.

13 Chaudhary A, Fresquez TM, Naranjo MJ: Tyrosine kinase Syk associates with toll-like receptor 4 and regulates signaling in human monocytic cells. Immunol Cell Biol 2007;85:249-256.

14 Bae YS, Lee JH, Choi SH, Kim S, Almazan F, Witztum JL, Miller YI: Macrophages generate reactive oxygen species in response to minimally oxidized low-density lipoprotein: toll-like receptor 4- and spleen tyrosine kinase-dependent activation of NADPH oxidase 2. Circ Res 2009;104:210-218.

15 Yanagi S, Inatome R, Takano T, Yamamura H: Syk expression and novel function in a wide variety of tissues. Biochem Biophys Res Commun 2001;288:495-498.

16 Kim YJ, Koo TY, Yang WS, Han NJ, Jeong JU, Lee SK, Park SK: Activation of spleen tyrosine kinase is required for TNF- $\alpha$-induced endothelin-1 upregulation in human aortic endothelial cells. FEBS Lett 2012;586:818826.

17 Yang WS, Seo JW, Han NJ, Choi J, Lee KU, Ahn H, Lee SK, Park SK: High glucose-induced NF-кB activation occurs via tyrosine phosphorylation of $\mathrm{I} \kappa \mathrm{B} \alpha$ in human glomerular endothelial cells: involvement of Syk tyrosine kinase. Am J Physiol Renal Physiol 2008;294:F1065-F1075.

18 Yang WS, Chang JW, Han NJ, Lee SK, Park SK: Spleen tyrosine kinase mediates high glucose-induced transforming growth factor- $\beta 1$ up-regulation in proximal tubular epithelial cells. Exp Cell Res 2012;318:1867-1876.

19 Zhang J, Billingsley ML, Kincaid RL, Siraganian RP: Phosphorylation of Syk activation loop tyrosines is essential for Syk function. An in vivo study using a specific anti-Syk activation loop phosphotyrosine antibody. J Biol Chem 2000;275:35442-35447.

20 Matsunaga N, Tsuchimori N, Matsumoto T, Ii M: TAK-242 (resatorvid), a small-molecule inhibitor of Tolllike receptor (TLR) 4 signaling, binds selectively to TLR4 and interferes with interactions between TLR4 and its adaptor molecules. Mol Pharmacol 2011;79:34-41.

21 Newton K, Dixit VM: Signaling in innate immunity and inflammation. Cold Spring Harb Perspect Biol 2012;4:a006049.

22 Mollica L, De Marchis F, Spitaleri A, Dallacosta C, Pennacchini D, Zamai M, Agresti A, Trisciuoglio L, Musco G, Bianchi ME: Glycyrrhizin binds to high-mobility group box 1 protein and inhibits its cytokine activities. Chem Biol 2007;14:431-441.

23 Vig E, Green M, Liu Y, Donner DB, Mukaida N, Goebl MG, Harrington MA: Modulation of tumor necrosis factor and interleukin-1-dependent NF- $\kappa B$ activity by mPLK/IRAK. J Biol Chem 1999;274:13077-13084.

24 Kim JM, Cho HH, Lee SY, Hong CP, Yang Jw, Kim YS, Suh KT, Jung JS: Role of IRAK1 on TNF-induced proliferation and NF- $\kappa$ B activation in human bone marrow mesenchymal stem cells. Cell Physiol Biochem 2012;30:49-60. 
25 Musumeci D, Roviello GN, Montesarchio D: An overview on HMGB1 inhibitors as potential therapeutic agents in HMGB1-related pathologies. Pharmacol Ther 2014;141:347-357.

26 Wang H, Vishnubhakat JM, Bloom O, Zhang M, Ombrellino M, Sama A, Tracey KJ: Proinflammatory cytokines (tumor necrosis factor and interleukin 1) stimulate release of high mobility group protein-1 by pituicytes. Surgery 1999;126:389-392.

27 Wang H, Bloom O, Zhang M, Vishnubhakat JM, Ombrellino M, Che J, Frazier A, Yang H, Ivanova S, Borovikova L, Manogue KR, Faist E, Abraham E, Andersson J, Andersson U, Molina PE, Abumrad NN, Sama A, Tracey KJ: HMG-1 as a late mediator of endotoxin lethality in mice. Science 1999;285:248-251.

28 Willenbrock S, Braun O, Baumgart J, Lange S, Junghanss C, Heisterkamp A, Nolte I, Bullerdiek J, Murua Escobar H: TNF- $\alpha$ induced secretion of HMGB1 from non-immune canine mammary epithelial cells (MTH53A). Cytokine 2012;57:210-220.

29 Yang WS, Lee JM, Han NJ, Kim YJ, Chang JW, Park SK: Mycophenolic acid attenuates tumor necrosis factor- $\alpha$ induced endothelin-1 production in human aortic endothelial cells. Atherosclerosis 2010;211:48-54.

30 Reczek CR, Chandel NS: ROS-dependent signal transduction. Curr Opin Cell Biol 2015;33:8-13.

31 Cui Y, Xie X, Jia F, He J, Li Z, Fu M, Hao H, Liu Y, Liu JZ, Cowan PJ, Zhu H, Sun Q, Liu Z: Ambient fine particulate matter induces apoptosis of endothelial progenitor cells through reactive oxygen species formation. Cell Physiol Biochem 2015;35:353-363.

32 Choi SH, Harkewicz R, Lee JH, Boullier A, Almazan F, Li AC, Witztum JL, Bae YS, Miller YI: Lipoprotein accumulation in macrophages via toll-like receptor-4-dependent fluid phase uptake. Circ Res 2009;104:1355-1363. 